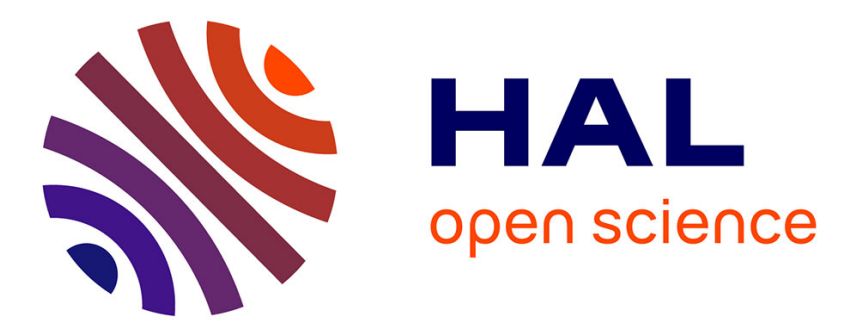

\title{
Development of a Collaborative Platform for Closed Loop Production Control
}

Ben Luetkehoff, Matthias Blum, Moritz Schroeter

\section{To cite this version:}

Ben Luetkehoff, Matthias Blum, Moritz Schroeter. Development of a Collaborative Platform for Closed Loop Production Control. 19th Working Conference on Virtual Enterprises (PRO-VE), Sep 2018, Cardiff, United Kingdom. pp.278-285, 10.1007/978-3-319-99127-6_24 . hal-02191196

\section{HAL Id: hal-02191196 \\ https://hal.inria.fr/hal-02191196}

Submitted on 23 Jul 2019

HAL is a multi-disciplinary open access archive for the deposit and dissemination of scientific research documents, whether they are published or not. The documents may come from teaching and research institutions in France or abroad, or from public or private research centers.
L'archive ouverte pluridisciplinaire HAL, est destinée au dépôt et à la diffusion de documents scientifiques de niveau recherche, publiés ou non, émanant des établissements d'enseignement et de recherche français ou étrangers, des laboratoires publics ou privés. 


\title{
Development of a Collaborative Platform for Closed Loop Production Control
}

\author{
Ben Luetkehoff, Matthias Blum and Moritz Schroeter \\ ${ }^{1}$ FIR at RWTH Aachen University, Production Management, Campus-Boulevard 55, 52074 \\ Aachen, Germany \\ $\{1 h, b l, s c h\} @$ fir.rwth-aachen.de
}

\begin{abstract}
In today's turbulent market, the way data are used in production is one of the key aspects to maintain or increase a manufacturing company's ability to compete. Even though most companies are aware of the advantages of collecting, analyzing and using data, the majority of them do not exploit these fully. Thus, IT systems and sensors are integrated into the shop floor in order to deal with the current challenges, leading to an overwhelming amount of data without contributing to an improvement of production control. Because of developments like digitization and Industry 4.0, there is an innumerable amount of existing research focusing on data analytics, artificial intelligence and pattern recognition. However, research on collaborative platforms in traditional production control still needs improvement. Therefore, the main goal of this paper is to present a platform based closed loop production control and to discuss the relevant data. The collaborative platform represents the basis for a future analysis of high-resolution data using cognitive systems in order for companies to maximize the automation of their production. A use case at the end of the paper shows the potential implementation of the findings in practice.
\end{abstract}

\section{Introduction}

Manufacturing companies no longer only produce products - they also produce data. Industry 4.0 and the Internet of Things are some of the reasons for the immense increase in data collection on the shop floor. However, simply collecting various amounts of data is not enough. Ideally, the data collected are used to improve the production processes by reducing and controlling the growing complexity. In fact, a full exploitation of the generated data is necessary for an improvement of production control by analyzing the collected data, finding patterns and returning drawn conclusions into the system $[1,2]$. The goal of the research project "Intelligent Production Control" (iProd) is to use the data produced on the shop floor and along the order execution process, collect it on a shared platform and use Artificial Intelligence to recognize patterns and use the results to control the production [3].

A support system, such as the one being developed in the research project, is necessary to support agile processes [4] and because of the limited capabilities of employees when it comes to the detection and eliminations of disturbances [5]. Collaborative data platforms represent a high value for companies as long as more 
than one use it. This means that the more users adopt and contribute to a platform, the more valuable it becomes [6]. This is relevant in the big picture because most big data analyses are based on inflexible heuristic optimizations and static analyses. However, companies still need to put a lot of effort into the development of a self-learning closed loop production control that eliminates deviations and disturbances independently $[7,8]$. The first step into that direction is the collection and storing of relevant data from the shop floor and IT systems used for the order processing.

The goal of this paper is to develop and present the idea of a collaborative platform-based closed loop production control by demonstrating how to collect relevant data. The analysis of the data is supposed to enable companies to improve their order processing processes in the end.

First, we outline the motivation of the paper and give a short overview of the relevant state of the art. Building on the state of the art, we discuss the relevant requirements before we show the application of the concept within a use case of one research partner. To conclude we summarize the findings and discuss the future research.

\section{Motivation for the Collaborative Platform}

A constantly rising flood of data already is and will be unavoidable in the future. The question that arises is which data to collect and how to handle it [9]. Since data is automatically collected, it should be made use of. However, there are "various challenges related to accessing and managing all relevant data [...]" [10]. The problem is the storing of information on different levels and systems in a company, leading to a heterogeneous landscape and a difficulty in gaining knowledge from the data.

A solution to the problem where to store and how to handle data are collaborative data platforms. Data platforms represent a high value to companies as long as more than one use them. This means that the more users adopt and contribute to a platform, the more valuable it becomes to each user.

Collective intelligence is defined as "an emergent property from synergies among three elements: 1) data knowledge; 2) software; 3) experts and others with insight that continually learns from feedback to produce just-in-time knowledge for better decisions than any of these elements acting alone" [11].

Therefore, the motivation for this research is to gain knowledge from data generated by different companies, use a collaborative platform to analyze the data and feed it back to the companies to support the experts.

\section{State of the Art}

In this section, the basics of production control are reviewed and the basic principles of platforms, data collection, IT systems and their application in production planning and control are discussed. 
In general, there are two important differences between open loop production control and closed loop production control, i.e. feedback mechanisms. The advantage of closed loop production control is an increased reaction speed when disturbances occur [12]. Just like in control theory, the production represents the closed loop controlled system (see Fig. 1 below) whose actuating variables can be derived from the production [13].

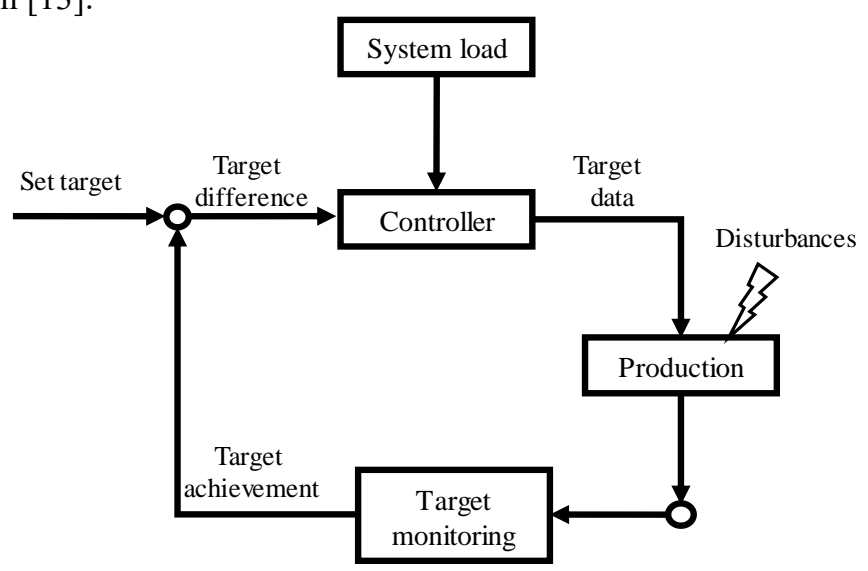

Fig. 1 Production control [13]

Industry platforms are products, services, or technologies developed by one or more companies, and which serve as a basis for a larger number of companies to "build further complementary innovations and potentially generate network effects" [6]. When looking at software companies such as Microsoft or SAP, platforms are becoming more and more popular in many fields. This may be because a high amount of data can be processed in a short period. Moreover, platforms can be considered as a "growing set of complementary innovations" and advantages come along when they are used [6].

In companies many heterogeneous IT systems exist that are supposed to manage the production planning and control. Two of the main systems for this task are Enterprise Resource Planning (ERP) and Manufacturing Execution Systems (MES) [14]. Research on closed loop production control, which means adding an additional feedback loop to the open loop production control, is found in several publications [7, 15, 16]. However, since they are mostly based on discrete-event simulation, they require a lot of manual effort and the automation of said models has solely been discussed theoretically [17].

The data from the production needs to be up-to-date and interpretable by machines [2]. Part of the information is the production data (e.g. sensor data) itself and their data points, which is necessary to filter by relevance. In order to do this, a domainspecific information model needs to be developed. Domain Specific Languages (DSL) and Open Platform Communication (OPC) are necessary to model complex automation systems such as the proposed platform [18]. They are supposed to improve the monitoring and control of systems in production [19]. 
Overall, platforms are becoming more and more popular in many fields because of the possibility to transfer a high amount of data in a short period. Moreover, the necessary data for a closed loop production control can nowadays be generated and analyzed. However, existing approaches and products neglect the fact that the data from one system may not be enough and the platforms need to be fed by more than just one IT-System in order to generate reliable results.

\section{Requirements}

There are four basic requirements for the proposed concept to establish a collaborative platform. The first element (A) presents the process of data collection in general and describes which actuating variables to collect from the production and where this data can be captured. The second element (B) describes the data platform with of the collected data. Steps (C) and (D) deal with finding methods to analyze data and recognize pattern as well as the recirculation of the results into the system. This paper focusses on the first two elements since the last two elements are still being researched and will be published later.

\section{A) Data collection}

Before uploading data to the platform, it needs to be collected throughout the different enterprise levels of a company. Within the framework of this paper, the considered levels will be the shop floor, the Manufacturing Execution System (MES) and the Enterprise Resource Planning (ERP) (see Fig. 2).

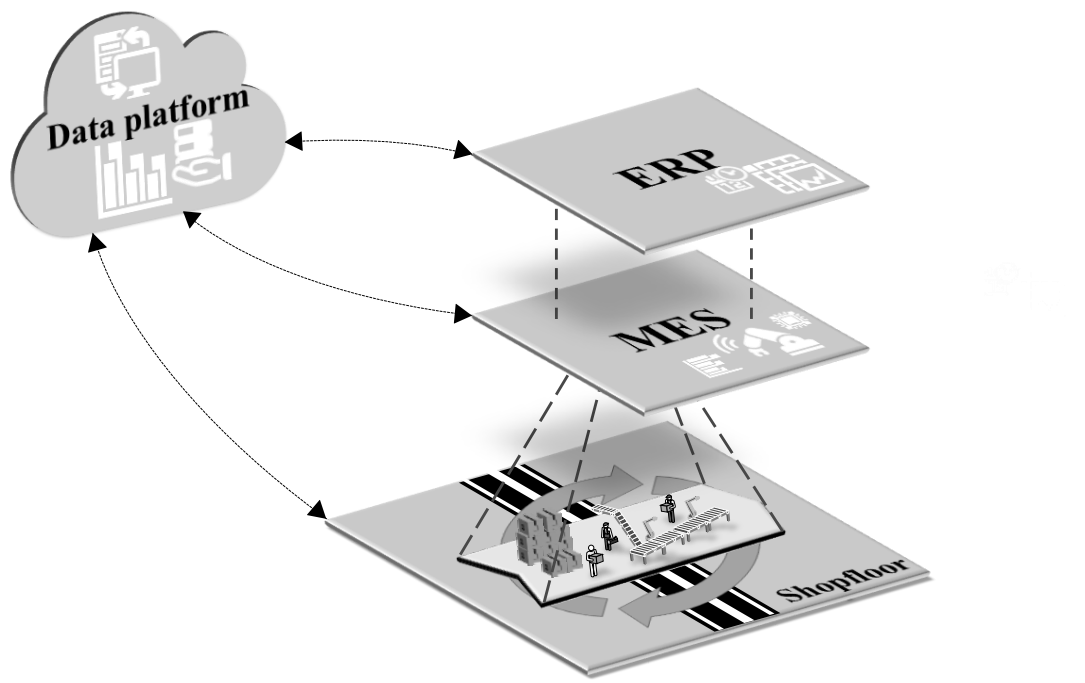

Fig. 2 Data exchange and access between enterprise levels and the data platform 
The basis for a real time closed loop production control is high-resolution shop floor data. Part of the relevant data is manufacturing, energy consumption and production data. The production data can be machine data (and tool data) or process and quality data that originates from sampling, measuring and testing data [20]. Moreover, smart object data is collected on the shop floor by using systems such as Real Time Location Systems (RTLS). Shop floor data is available close to real time, meaning that data is generated every minute, second or millisecond.

The ME-System exchanges data with the ERP-system regarding the management level [21] and receives and processes, among other things, data from the shop floor. Data that an MES is able to record can either be internal or external [20]. The MEsystem is able to check the collected data, e.g. from the shop floor, for plausibility, which can contribute to guaranteeing high data quality.

Table 1 Internal and External data sources in ME-Systems [20]

\begin{tabular}{|l|l|}
\hline Internal sources & External sources \\
\hline Finely planned production & $\begin{array}{l}\text { Goods receipt slips, vendor and customer } \\
\text { information }\end{array}$ \\
\hline Orders, process data, process information & $\begin{array}{l}\text { Information from other systems participating } \\
\text { in quality assurance }\end{array}$ \\
\hline $\begin{array}{l}\text { Material status, claim information, additional } \\
\text { inspection }\end{array}$ & CAD, PLM, and smart objects \\
\hline Requirements due to special circumstances & $\begin{array}{l}\text { Order data from the data of ERP/PPS } \\
\text { production orders }\end{array}$ \\
\hline Personnel qualifications & \\
\hline
\end{tabular}

ERP Systems generally deal with all the necessary data along the order processing. Therefore, it mainly comprises all data related to orders. The borders between the three enterprise levels cannot be separated clearly, as they overlap and exchange information - especially ERP and ME-Systems share much of the data. The main difference is the fact that ERP-systems do usually not have capacity data.

Moreover, the three levels cover different timescales leading to varying effects of the transferred data on the closed loop production control. The Enterprise Resource Planning is used for production scheduling within several weeks or months, whereas the time horizon of the shop floor can vary between minutes or milliseconds. The Manufacturing Execution System is located in between those two levels, enabling a supply of information among them. [21]

\section{B. Data platform}

The data collected from the three systems mentioned above are transferred to the collaborative platform. The data platform provides the basis for real-time pattern recognition through artificial intelligence. In order to draw valuable conclusions from the data, a filter needs to be applied beforehand to ensure that only data whose evaluation will lead to significant results is generated and uploaded. Depending on the companies in focus and their production processes, the data may vary. There are 
multiple ways of implementing a new data platform, depending on each company's preferences regarding data sharing, local accessibility and provision of data for others.

Possible implementation potentials would be a cloud solution if the company shares collected data and analyses with other companies with access to the platform. An in-house solution could be implemented if the platform is only applied within one company or if the company demands private access to collected and analyzed data (Fig. 3). Within the range of this paper, a cloud solution is used, as several companies are accessing and contributing to the platform. The established collaborative data platform operates acts as a decision support system.

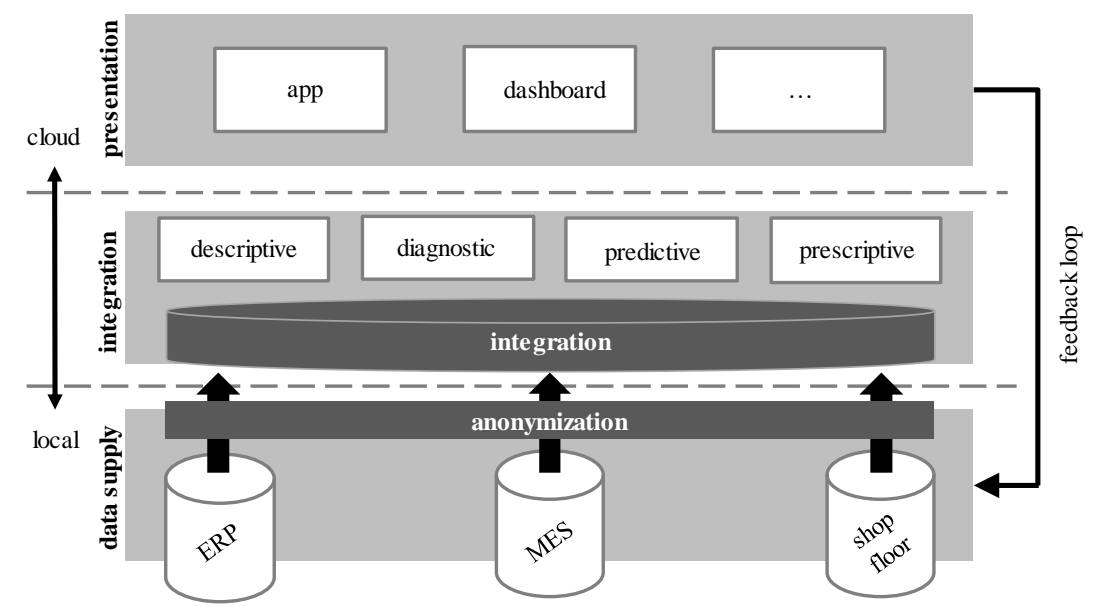

Fig. 3 Cloud vs. in-house platform solution

\section{Use Case}

The company in focus produces foils and foil products (e.g. plastic bags) in three shifts with around 50 employees. Because of its relatively small size and standardized processes, the sales team can accept and loosely plan orders based on the remaining capacity in production and customer order specifications. Roughly two weeks before the start of production, the production manager reviews the planned orders and manually adjust them to fit the schedule based on the given constraints. Currently, a lot of manual planning and implicit knowledge of the production manager is required, especially when deviations occur.

In order to reduce the manual planning effort in production, the collective platform is supposed to analyze the relevant data and assist the management by generating response strategies and giving decision support. The necessary data already mostly exists in the ERP-System with ME-functionalities:

- Order information, such as delivery date, quantity and recipe

- Production status, such as capacity, workload, personnel, material

- Machine specific information, such as producible products 
The manual effort was necessary because machine specific information has been part of the production manager's implicit knowledge and not shared with the system. Since this is of vital importance for the production planning, this data had to be formalized and introduced into the system.

\section{Conclusion and Further Research}

In today's turbulent market, manufacturing companies need to make use of every resource available to them. One of the biggest and mostly untapped supply of optimization potential is the way companies use data. Because of the continuing digitization and developments like the Internet of Things and Industry 4.0 the amount of said data increases and is there for the taking.

The challenges companies face when it comes to using the data are threefold: Which data to collect, how to collect it and how to generate additional value through its analysis. Thus, the goal of this paper was to show how to deal with two of the previously mentioned challenges. The relevant data was discussed and it was shown where it can be found. Secondly, the concept of a platform as a means to collect the data and as a basis for the necessary analysis was introduced.

However, there is still a lot of research necessary to make full use of the data in the future. This research should focus on which methods of data analytics to use in order to generate value from the data. Moreover, the proposed concept only supports the experts' decision-making process. In the future, the research should focus on how to automate these processes even more.

\section{Acknowledgement}

The European Regional Development Fund (ERDF) funded the presented research. The authors would like to thank the European Regional Development Fund for the kind support and making this research possible.

\section{References}

1. Kropp SK (2016) Entwicklung eines Ereignismodells als Grundlage der Produktionsregelung, 1st edn. Schriftenreihe Rationalisierung, vol 137. Apprimus, Aachen

2. Schuh G, Blum M (2016) Design of a data structure for the order processing as a basis for data analytics methods. In: Portland International Conference on Management of Engineering and Technology (PICMET), Honolulu, pp 2164-2169

3. Luetkehoff B, Blum M, Schroeter M (2017) Self-learning Production Control Using Algorithms of Artificial Intelligence. In: Camarinha-Matos LM, Afsarmanesh H, Fornasiero R (eds) Collaboration in a Data-Rich World, vol 506. Springer International Publishing, Cham, pp 299-306 
4. Camarinha-Matos LM, Afsarmanesh H, Fornasiero R (eds) (2017) Collaboration in a Data-Rich World. IFIP advances in information and communication technology. Springer International Publishing, Cham

5. Meier C (2013) Echtzeitfähige Produktionsplanung und -regelung in der Auftragsabwicklung des Maschinen- und Anlagenbaus, 1st edn. Edition Wissenschaft, vol 117. Apprimus, Aachen

6. Gawer A, Cusumano MA (2014) Industry Platforms and Ecosystem Innovation. J Prod Innov Manag 31(3): 417-433. doi: 10.1111/jpim.12105

7. Hamann T (2008) Lernfähige intelligente Produktionsregelung. Informationstechnische Systeme und Organisation von Produktion und Logistik, vol 7. GITO, Heidelberg

8. Hauptvogel A (2015) Bewertung und Gestaltung von cyber-physischer Feinplanung, 1. Aufl. Produktionssystematik, vol 6. Apprimus Verlag, Aachen

9. Schuh G, Blum M, Reschke J et al. (2016) Der Digitale Schatten in der Auftragsabwicklung. ZWF: 48-51

10. Kassner L, Gröger C, Mitschang B et al. (2015) Product Life Cycle Analytics - Next Generation Data Analytics on Structured and Unstructured Data. Procedia CIRP: 35-40

11. Glenn JC (2013) Collective Intelligence and an Application by The Millennium Project. World Futures Review 5(3): 235-243. doi: 10.1177/1946756713497331

12. Wiendahl H-P (2014) Betriebsorganisation für Ingenieure, 8., überarb. Aufl. Hanser, München

13. Wiendahl H-P (1997) Fertigungsregelung: Logistische Beherrschung von Fertigungsabläufen auf Basis des Trichtermodells. Hanser, München

14. Kletti J, Schumacher J (2014) Die perfekte Produktion: Manufacturing Excellence durch Short Interval Technology (SIT), 2nd edn. Springer, Heidelberg

15. Simon D (1995) Fertigungsregelung durch zielgrößenorientierte Planung und logistisches Störungsmanagement. iwb Forschungsberichte, vol 85. Springer, Heidelberg

16. Zetlmayer H (1994) Verfahren zur simulationsgestützten Produktionsregelung in der Einzel- und Kleinserienproduktion. iwb Forschungsberichte, Bd. 74. Springer, Berlin, New York

17. Selke C (2005) Entwicklung von Methoden zur automatischen Simulationsmodellgenerierung, vol 193. Utz, München

18. Fowler M (2011) Domain-specific languages: Description based on print version record. - "A Martin Fowler signature book."--Cover. Addison-Wesley signature series. AddisonWesley, Upper Saddle River, N.J.

19. Goldschmidt T (2014) Towards an Infrastructure for Domain-Specific Languages in a Multi-domain Cloud Platform. In: Cabot J, Rubin J (eds) Modelling Foundations and Applications, vol 8569. Springer International Publishing, Cham, pp 242-253

20. VDI R (2007) 5600, Manufacturing Execution Systems. Verein Deutscher Ingenieure

21. Kletti J (2006) MES - Manufacturing Execution System: Moderne Informationstechnologie Zur Prozessfähigkeit Der Wertschöpfung. Springer, Dordrecht 